\title{
Lower Lobe of the Lung
}

National Cancer Institute

\section{Source}

National Cancer Institute. Lower Lobe of the Lung. NCI Thesaurus. Code C12287.

The bottom most subdivision of either the right or left lung. 